International Journal of Pure and Applied Mathematics

Volume 106 No. 2 2016, 365-380

ISSN: 1311-8080 (printed version); ISSN: 1314-3395 (on-line version)

url: http://www.ijpam.eu

doi: 10.12732 /ijpam.v106i2.2

\title{
THE ROLE OF DYNAMIC PROGRAMMING IN THE DISTRIBUTION OF INVESTMENT ALLOCATIONS BETWEEN PRODUCTION LINES WITH AN APPLICATION
}

\author{
Inam Abdul-Zahra ${ }^{3}$, Iraq Tereq Abbas ${ }^{1,2} \S$, Bayda Atiya Kalaf ${ }^{1}$, \\ Rizam Abu Bakar ${ }^{1}$, Leong Wah June ${ }^{1}$, Mansor Bin Monsi ${ }^{1}$ \\ ${ }^{1}$ Department of Mathematics \\ Faculty of Science \\ University Putra Malaysia \\ ${ }^{2}$ University of Baghdad \\ Faculty of science \\ Department of Mathematics \\ ${ }^{3}$ University of Kufa \\ College of Administration and Economics
}

\begin{abstract}
At present, the ability to promote national economy by adjusting to political, economic, and technological variables is one of the largest challenges faced by organization productivity. This challenge prompts changes in structure and line productivity, given that cash has not been invested. Thus, the management searches for investment opportunities that have achieved the optimum value of the annual increases in total output value of the production line workers in the laboratory. Therefore, the application of dynamic programming model is adopted in this study by addressing the division of investment expenditures to cope with market-dumping policy and to strive non-stop production at work.
\end{abstract}

Key Words: sensitively analysis, production planning, decision maker, linear programming

Received: May 21, 2015

Published: February 9, 2016

${ }^{\S}$ Correspondence author
(C) 2016 Academic Publications, Ltd. url: www.acadpubl.eu 


\section{Scientific Methodology to Search}

\subsection{Problem of the study}

Indivisible cash with ready-made garment factory management in Najaf is available to a range of alternatives to investment opportunities. Moreover, the problem is how to distribute the cash among five production lines (i.e., $A_{1}, A_{2}$, $A_{3}, A_{4}$, and $\left.A_{5}\right)$ working in the laboratory. This laboratory achieves optimal value of total annual increases in the production and value of five production lines.

\subsection{Aim of the study}

Dynamic programming is applied to address the division of investment expenditure in accordance with the alternative investment opportunity problem model. Moreover, it aims to achieve the optimal value of total annual increases in production value for each of the five production lines owned by the garment factory.

\subsection{Research Hypothesis}

\subsection{Mathematical Model for Dynamic Programming}

The basic trait that characterizes dynamic programming is to enter the time element in the sports of the problem model instead of the case in linear programming or other types of relevant fixed mathematical formulas and sports programming models. Under this method, decision makers can plan optimization of operations and change adjustment over time, that is, the dynamic programming athlete user approach in addressing problems throughout the implementation of processes is used by solving these problems to reach the optimal method of change required by the problem and the amendment in the dynamic programming frame (which leads to a series of decisions). The problem is divided into several successive stages. In particular, some of these problems may be naturally divided, whereas others should be manually divided.

The idea of dynamic programming assumes that several stages of the problem of the organization exist, including certain acts consisting of $\mathrm{N}$ of sequential stages. Thus, it is at the beginning stage. The idea of dynamic programming assumes that several stages of the problem of the organization exist, including certain acts consisting of $\mathrm{N}$ of sequential stages. Thus, it is at the be- 
ginning stage. (Where $n=1,2, \ldots, N)$ The value of the base variable (Xn) should be determined. The basic variable series $\left(X_{1}, X_{2}, \ldots, X_{n}, \ldots, X_{N}\right)$ of productive activity should also be determined as a whole, and they should be selected through the way standards that result from determining $\mathrm{F}$ function $\left(X_{1}, X_{2}, \ldots, X_{n}, \ldots, X_{N}\right)$ are made. This function has a maximum or minimum value, according to the nature of the problem. When making a particular decision on one stage, the other relay is not neglected, and all the other stages are considered. Therefore, we can conclude that in light of dynamic programming, the optimal solution in several stages according to the sequence of activity is being sought. Each stage is optimized, and the decision taken in one of the stages of activity has a close link to the decision in the other stages. The basic rule adopted in finding ideal solution based on dynamic programming model is used to address a particular system as follows: Regardless of the primary system status and primary decision, subsequent decisions should represent the best policy based on the situation resulting from the primary decision to clarify that we placed the following hypotheses.

$S_{t}$ - If the problem system is at the moment t (position in the previous case).

$S_{t+1}$ - If the problem system state is at the moment $\mathrm{t}+1$ (current situation). $D_{t+1}$ - If the decision taken at the moment is $t+1$ (current resolution). $\mathrm{F}$ - objective function

Therefore

$$
S_{t+1}=F\left(S_{t}, d_{t+1}\right) .
$$

Thus, the system status at the moment $t+1$ is a case in a function of the system in the previous position (primary moment) with the decision taken at the moment $(t+1)$ or the present moment. Moreover, readers may assume that the problem is the decision in a certain system.

Regarding the distribution of basic production requirements that the amount of a unit, and that between $\mathrm{N}$ of $\operatorname{activities}(n=1,2, \ldots N)$ is with all $\mathrm{n}$ of activities there are the results of a function (goal) is linked to it, and symbolizes the function mentioned that should lead us to the optimal case as follows: $g_{n}\left(X_{n}\right)$

Where: $X_{n}=$ the amount of basic necessities, which are distributed among the activities, based on what progress can formulate a mathematical model dynamic private optimum distribution of basic requirements for production, as follows: Required to determine the positive values of the basic variables unknowns $X_{1}, X_{2}, \ldots, X_{n}, \ldots X_{N}$. Here: $X_{n}$ is the amount of basic necessities for the specific activity of the type and $\mathrm{n}$ is the desired objective function:

$$
F\left(X_{1}, X_{2} \ldots X_{n}, \ldots X_{N}\right)=g_{1}\left(X_{1}\right)+g_{2}\left(X_{2}\right)+\ldots+g_{n}\left(X_{n}\right)+\ldots g_{N}\left(X_{N}\right) .
$$


Fulfills the following conditions:

$$
X_{1}+X_{2}+\ldots+X_{n}, \ldots, \quad X_{N}=A .
$$

In terms of the conditions mentioned conclude that the available quantity of certain basic necessities.

\section{The Practical Framework of the Research}

\subsection{Overview Men's clothing factory}

Men's ready-made clothing factory in Najaf was established under the second paragraph of Article IV of the Public Institutions LawNo.(90)of1970, as the project was created in the period between $18 / 05 / 1980$ and 04/30/1983 but was receiving for the project in July1985 after reaching a settlement with the company executing formula because of delays, the trial run was a period between 1986 and 1987, while commercial production began in 1988.

Laboratory (16) line production specialist produces mens clothing. This plant is the largest in Iraq, as well as in Middle East, as it was designed to produce 2 million pieces per year. In 1987, it merged with the laboratory with modern sewing factory in Baghdad. In 1988, it then merged with General Company garments in Mosul establishment, which was one of the plants of mens clothing factory in Najaf.

As a result of military operations in Iraq in 2003, the plant was exposed to aerial bombardment and the work and up to $90 \%$ individuals that operate in machinery and equipment stopped. This break lasted up to 2005, when the company has been rehabilitated and linked administratively with State Company for Textile Industries of the Ministry of Industry card design $(726,000)$ piece in2010. In2011, the amounted energy (926.000) after the opening of the project, namely, Mens Suit, developed the line. In the years2012 and2013, the plant was assigned for the production of private military suits and police and military suits, as these types of suits are characterized with required coarseness and complexities for the purposes of protection. Thus, the workers in the laboratory strives management to restructure production lines by providing them with a range of machinery and equipment and to invest additional cash in the necessary production lines. The company has chosen five production lines(i.e., $A_{1}, A_{2}, A_{3}, A_{4}$, and $A_{5}$ ), which are shown in Figure (1), for the purposes of this new orientation toward production. These machines were originally designed to produce clothing that is characterized by smooth and light 
production and based on laboratory management toward responding to these changes to cope with dumping market policy and to strive to continue non-stop production at work.

\subsection{Problem statements}

Figure (1) clearly illustrates that the laboratory is based on productive activities on five production lines(i.e., $A_{1}, A_{2}, A_{3}, A_{4}$, and $\left.A_{5}\right)$, where the internal encoding for the site is the number of production lines (5). Therefore,

- $A_{1}=(5.1 / \mathrm{a}, 5.1 / \mathrm{b})$,

- $A_{2}=(5 . / \mathrm{a})$,

- $A_{3}=(5 . / \mathrm{a}, 5.1 / \mathrm{b})(5.1 / \mathrm{a}-\mathrm{c})$,

- $A_{4}=(5.1 / \mathrm{b}+5.1 / \mathrm{a}-\mathrm{c})(5.3)$,

- $A_{5}=(5.4)$.

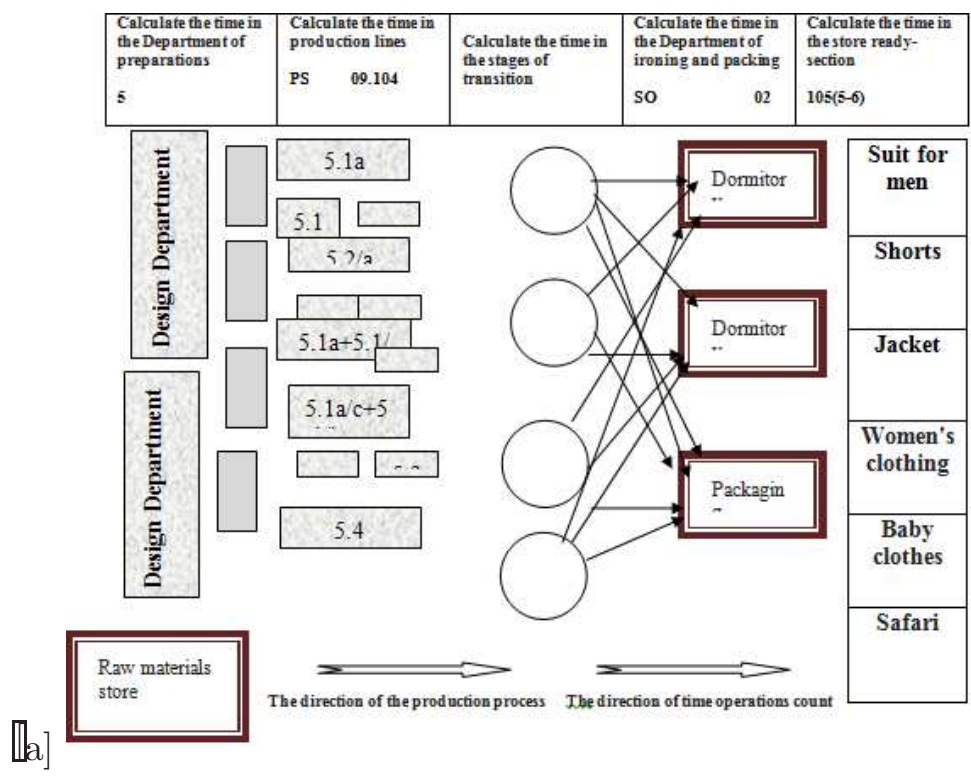

Through the case analysis, based on data received from the accounts department of planning and follow-up, it is clear that the management of the plant 
has four types of alternative plans or investment opportunities, so that the necessary financial needs of each alternative are:

- Variant+no.150thousand units of cash

- Variant + no.2 100 thousand units in cash

- Variant + no.3 150 thousand units in cash

- Variant + no.4 200 thousand units in cash

With regard to investment needs of each investment line, the most that can be up to him are as follows $(0,50,100150200)$ As for the annual increase that could be achieved in the volume of production for each production line to exploit what is contained above, it is clear from the following table:

\begin{tabular}{|c|l|l|l|l|l|l|}
\hline $\begin{array}{l}\text { Alternatives (op- } \\
\text { portunities) }\end{array}$ & The value & \multicolumn{5}{|l|}{ The value of the annual increase } \\
Investment & $\begin{array}{l}\text { of the } \\
\text { investment } \\
\text { needs }\end{array}$ & \multicolumn{5}{|c|}{$\begin{array}{l}\text { in the volume of production achieved } \\
\text { for each production line }\end{array}$} \\
\cline { 2 - 7 } & 0 & $A_{1}$ & $A_{2}$ & $A_{3}$ & $A_{4}$ & $A_{5}$ \\
\cline { 2 - 7 } & 0 & 25 & 30 & 36 & 28 & 32 \\
\hline Variant no.1 & 50 & 70 & 70 & 64 & 56 & 80 \\
\hline Variant no.2 & 100 & 100 & 90 & 95 & 110 & 105 \\
\hline Variant no.3 & 150 & 140 & 122 & 130 & 146 & 135 \\
\hline Variant no.4 & 200 & & & & & \\
\hline
\end{tabular}

Table 1: The amount of annual increases achieved in the volume of production for each production line and the four alternatives of investment disciplines.

From the table above it is clear that if the investment expenditure (100) thousand monetary units, the annual increase achieved in the volume and value of production and productivity of the lines $\left(A_{1}, A_{2}, A_{3}, A_{4}, A_{5}\right)$ are respectively: $(70,70,64.56,80)$. 


\subsection{Application of the Mathematical Model and Extraction of the Final Results}

\subsection{Definitions of the Mathematical Model}

In order to apply the mathematical model, which initially requires the identification of the following definitions: $\mathrm{Xi}=$ size required for the line of productive investment expenditure $(i) \quad(i=1,2,3,4,5)$

$g_{i}\left(X_{i}\right)=$ the amount of the annual increase in production occurring in the production line (i) due to exchange capital expenditure $\left(X_{i}\right) \quad(i=1,2,3,4,5)$

Thus, the total value of annual increases in production and productivity of the lines is calculated as follows:

$$
F\left(X_{1}, X_{2}, X_{3}, X_{4}, X_{5}\right)=g_{1}\left(X_{1}\right)+g_{2}\left(X_{2}\right)+g_{3}\left(X_{3}\right)+g_{4}\left(X_{4}\right)+g_{5}\left(X_{5}\right) .
$$

Here the variables $\left(X_{1}, X_{2}, X_{3}, X_{4}, X_{5}\right)$ must check the following condition:

$$
X_{1}+X_{2}+X_{3}+X_{4}+X_{5}=A_{5}
$$

here:

$$
X_{1} \geq 0, X_{2} \geq 0, X_{3} \geq 0, X_{4} \geq 0, X_{5} \geq 0
$$

( $i=1,2,3,4,5) \quad A_{i}=$ the total value of the calculated size of the branch of investment expenditure (i).

\subsection{Application of the Mathematical Model}

In the beginning is determined $X_{5}$ of investment expenditure for the production line $A_{5}$, the return is for an annual increase in production of $g_{5}\left(X_{5}\right)$ note that the $X_{5}$ should achieve the following condition:

Accordingly, the remainder of the capital expenditures for the rest of the production lines at the plant under study is calculated as follows:

$$
A_{4}=A_{5}-X_{5}
$$

Accordingly, the remainder of the investment expenditure a4 between production lines $\left(A_{1}, A_{2}, A_{3}, A_{4}\right)$ form that leads to obtain the optimum overall production increase. The total increase in the optimal production derived from the production lines $\left(A_{1}, A_{2}, A_{3}, A_{4}\right)$ realized on the basis of the remaining $A_{4}$ investment expenditure is calculated from the following relationship:

$$
F_{4}\left(A_{4}\right)=F_{4}\left(A_{5}-X_{5}\right)
$$


where: Based on the basic formula for linear programming described in the previous paragraph, if the value of the annual increase in the production of all production lines $\left(A_{1}, A_{2}, A_{3}, A_{4}\right.$, and $\left.A_{5}\right)$ is calculated from the following mathematical relationship:

$$
F_{5}\left(A_{5}\right)=\operatorname{Max}\left(g_{5}\left(X_{5}\right)+F_{4}\left(A_{5}-X_{5}\right)\right)
$$

As for the amount of the maximum total annual increases in production lines for the production of $\left(A_{1}, A_{2}, A_{3}\right.$, and $\left.A_{4}\right)$ is calculated as follows:

$$
F_{4}\left(A_{4}\right)=\operatorname{Max}\left(g_{4}\left(X_{4}\right)+F_{3}\left(A_{4}-X_{4}\right)\right)
$$

That for the rest of the production lines $\left(A_{1}, A_{2}\right.$, and $\left.A_{3}\right)$ is calculated as follows

$$
F_{3}\left(A_{3}\right)=\operatorname{Max}\left(g_{3}\right)\left(X+F_{2}\left(A_{3}-X_{3}\right)\right)
$$

Thus, for the branches $\left(A_{1}, A_{2}\right)$, where according to the principle of the optimal solution, it is possible to obtain the following functions:

That variable $A_{5}$ could take the values 50,100150200as listed in the table (1).

- For the variable $\left(X_{1}\right)$ :

$$
\begin{aligned}
F_{1}\left(A_{1}\right)= & \operatorname{Max}\left\{g_{1}\left(X_{1}\right)\right\} \\
& 0 \leq X_{1}=A_{1} \\
\text { Where } \quad & X_{1}=A_{1}
\end{aligned}
$$

- For the variable $\left(X_{2}\right)$ :

$$
\begin{aligned}
F_{2}\left(A_{2}\right)= & \operatorname{Max}\left\{\left(g_{2}\left(X_{2}\right)+F_{1}\left(A_{1}\right)\right\}\right. \\
0 \leq X_{2}= & A_{2} \\
= & \operatorname{Max}\left\{g_{2}\left(X_{2}\right)+F_{1}\left(A_{2}-X_{2}\right)\right\} \\
\text { Where } & A_{1}=A_{2}-X_{2}
\end{aligned}
$$

- For the variable $\left(X_{3}\right)$ :

$$
\begin{aligned}
F_{3}\left(A_{3}\right)= & \operatorname{Max}\left\{\left(g_{3}\left(X_{3}\right)+F_{2}\left(A_{2}\right)\right\}\right. \\
0 \leq X_{3}= & A_{3} \\
= & \operatorname{Max}\left\{g_{3}\left(X_{3}\right)+F_{2}\left(A_{3}-X_{3}\right)\right\} \\
\text { Where } & A_{2}=A_{3}-X_{3}
\end{aligned}
$$


- For the variable $\left(X_{4}\right)$ :

$$
\begin{aligned}
F_{4}\left(A_{4}\right)= & \operatorname{Max}\left\{\left(g_{4}\left(X_{4}\right)+F_{3}\left(A_{3}\right)\right\}\right. \\
0 \leq X_{4}= & A_{4} \\
= & \operatorname{Max}\left\{g_{4}\left(X_{4}\right)+F_{3}\left(A_{4}-X_{4}\right)\right\} \\
\text { Where } & A_{3}=A_{4}-X_{4}
\end{aligned}
$$

- For the variable $\left(X_{5}\right)$ :

$$
\begin{aligned}
F_{5}\left(A_{5}\right)= & \operatorname{Max}\left\{\left(g_{5}\left(X_{5}\right)+F_{4}\left(A_{4}\right)\right\}\right. \\
0 \leq X_{5}= & A_{5} \\
= & \operatorname{Max}\left\{g_{5}\left(X_{5}\right)+F_{4}\left(A_{5}-X_{5}\right)\right\} \\
& A_{4}=A_{5}-X_{5}
\end{aligned}
$$

Based on the relations of the above functions are optimal values the basic variables account $X_{i}=(i=1,2,3,4$, and5), and it also comes with:

- For the variable $\left(X_{1}\right)$ :

$$
\begin{aligned}
F_{1}\left(A_{1}\right)= & \operatorname{Max}\left\{g_{1}\left(X_{1}\right)\right\} \\
& 0 \leq X_{1}=A_{1} \\
\text { Where } \quad & X_{1}=A_{1}
\end{aligned}
$$

Where $A_{1}$ can take values $(0.50,100150200)$ and that, as in the following table:

\begin{tabular}{|c|c|}
\hline$X_{1}=A_{1}$ & $G_{1}=F_{1}\left(A_{1}\right)$ \\
\hline 0 & 0 \\
50 & 25 \\
100 & 70 \\
150 & 100 \\
200 & 140 \\
\hline
\end{tabular}

- For the variable $\left(X_{2}\right)$ :

$$
\begin{aligned}
F_{2}\left(A_{2}\right)= & \operatorname{Max}\left\{\left(g_{2}\left(X_{2}\right)+F_{1}\left(A_{1}\right)\right\}\right. \\
0 \leq X_{2}= & A_{2} \\
= & \operatorname{Max}\left\{g_{2}\left(X_{2}\right)+F_{1}\left(A_{2}-X_{2}\right)\right\} \\
\text { Where } & A_{1}=A_{2}-X_{2}
\end{aligned}
$$


After that is determined by the corresponding points of the variables $X_{2}, A_{1}$ and check that the following condition:

$$
A_{2}=A 1+X_{2} .
$$

Process $F_{2}$ account $\left(A_{2}\right)$ clear through the graph follows:

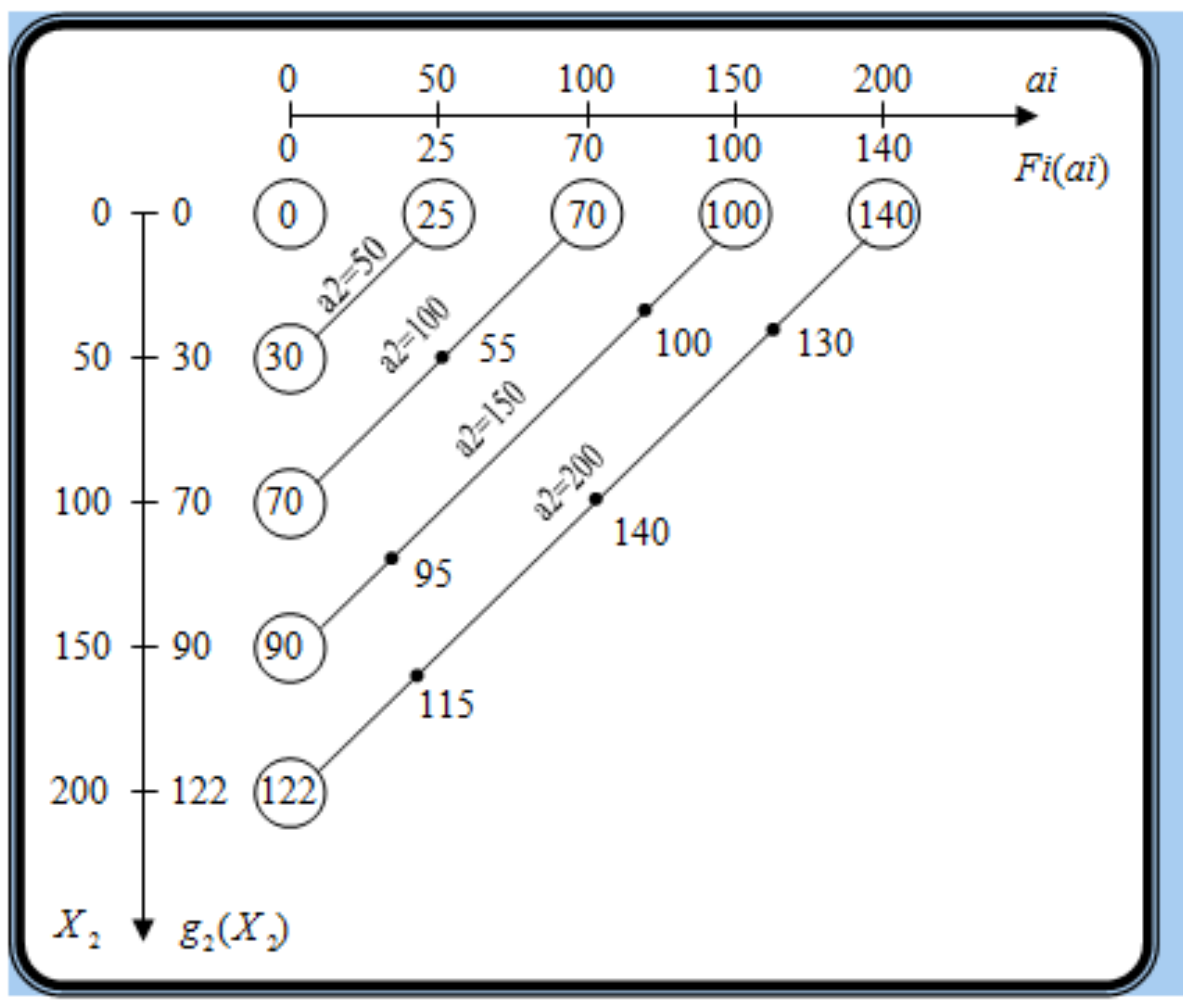

[la]

\section{Forms (2) calculate the amount of F2 (a2)}

As for the values of the variables $A_{2}, X_{2}$ (where $A_{2}=X_{2}+A_{1}$ ), it is calculated by the following table: 


\begin{tabular}{|c|c|c|c|}
\hline$A_{2}=A_{1}+X_{1}$ & $F_{2}\left(A_{2}\right)$ & $A_{1}$ & $X_{2}$ \\
\hline 0 & 0 & 0 & 0 \\
50 & 30 & 0 & 50 \\
100 & 70 & 100 & 0 \\
150 & 100 & 100 & 0 \\
200 & 140 & 200 & 0 \\
\hline
\end{tabular}

- For the variable $\left(X_{3}\right)$ :

$$
\begin{aligned}
F_{3}\left(A_{3}\right)= & \operatorname{Max}\left\{\left(g_{3}\left(X_{3}\right)+F_{2}\left(A_{2}\right)\right\}\right. \\
0 \leq X_{3}= & A_{3} \\
= & \operatorname{Max}\left\{g_{3}\left(X_{3}\right)+F_{2}\left(A_{3}-X_{3}\right)\right\} \\
\text { Where } & A_{3}=A_{2}-X_{3}
\end{aligned}
$$

The value of $F_{3}$ account $\left(A_{3}\right)$ for all $A_{3}$ on the basis of the values of the following forms:

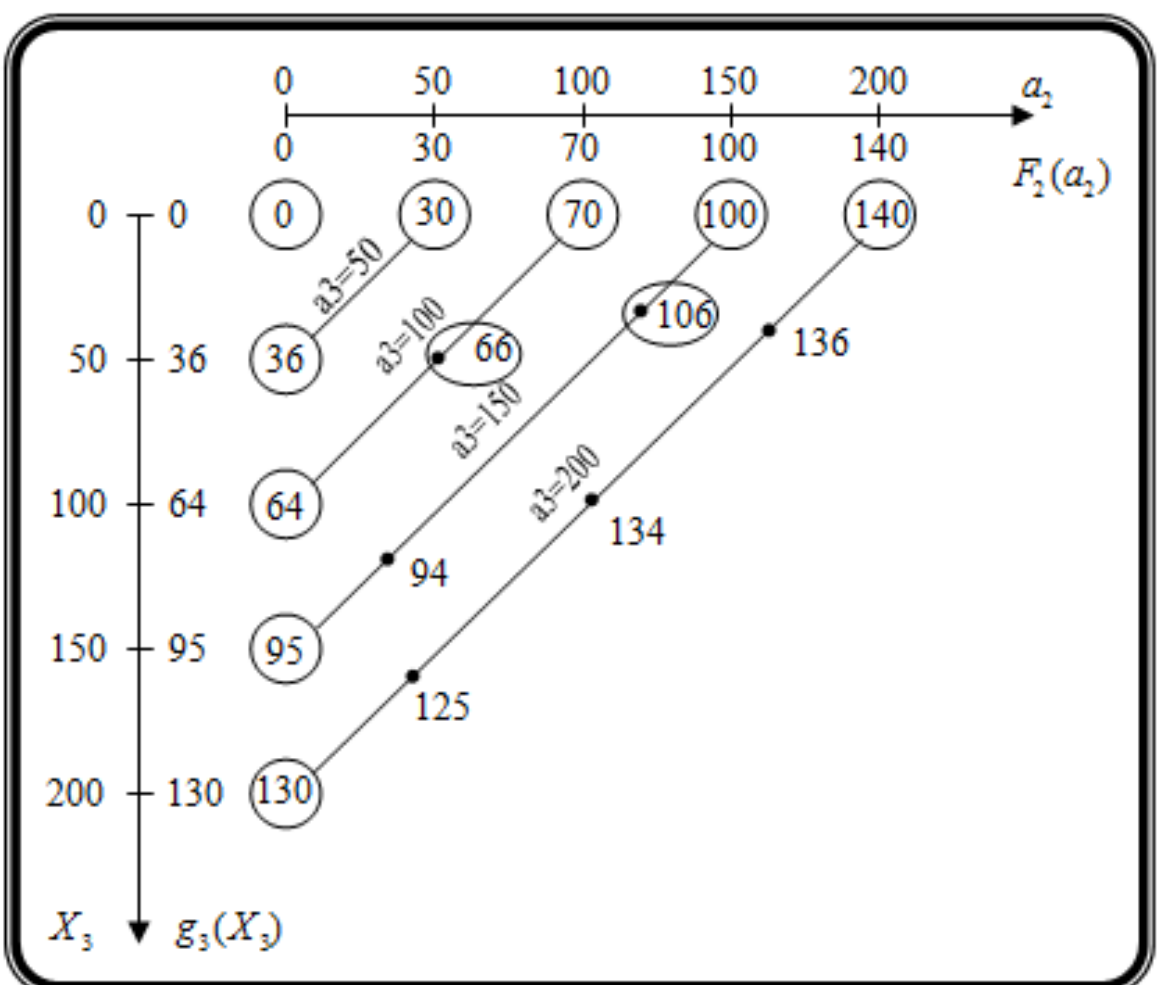

[a]

Form (3) calculates the value of F3 (a3) 
As for the variables $X_{3}, A_{2}$, it is calculated by the following table:

\begin{tabular}{|c|c|c|c|}
\hline$A_{3}=A_{2}+X_{3}$ & $F_{3}\left(A_{3}\right)$ & $A_{2}$ & $X_{3}$ \\
\hline 0 & 0 & 0 & 0 \\
50 & 36 & 0 & 50 \\
100 & 66 & 50 & 50 \\
150 & 106 & 100 & 50 \\
200 & 140 & 200 & 0 \\
\hline
\end{tabular}

- For the variable $\left(X_{4}\right)$ :

$$
\begin{aligned}
F_{4}\left(A_{4}\right)= & \operatorname{Max}\left\{\left(g_{4}\left(X_{4}\right)+F_{3}\left(A_{3}\right)\right\}\right. \\
0 \leq X_{4}= & A_{4} \\
= & \operatorname{Max}\left\{g_{4}\left(X_{4}\right)+F_{3}\left(A_{4}-X_{4}\right)\right\} \\
\text { Where } & A_{4}=A_{3}-X_{4}
\end{aligned}
$$

The value of $F_{4}$ account $\left(A_{4}\right)$ for all $A_{4}$ on the basis of the values of the following forms:

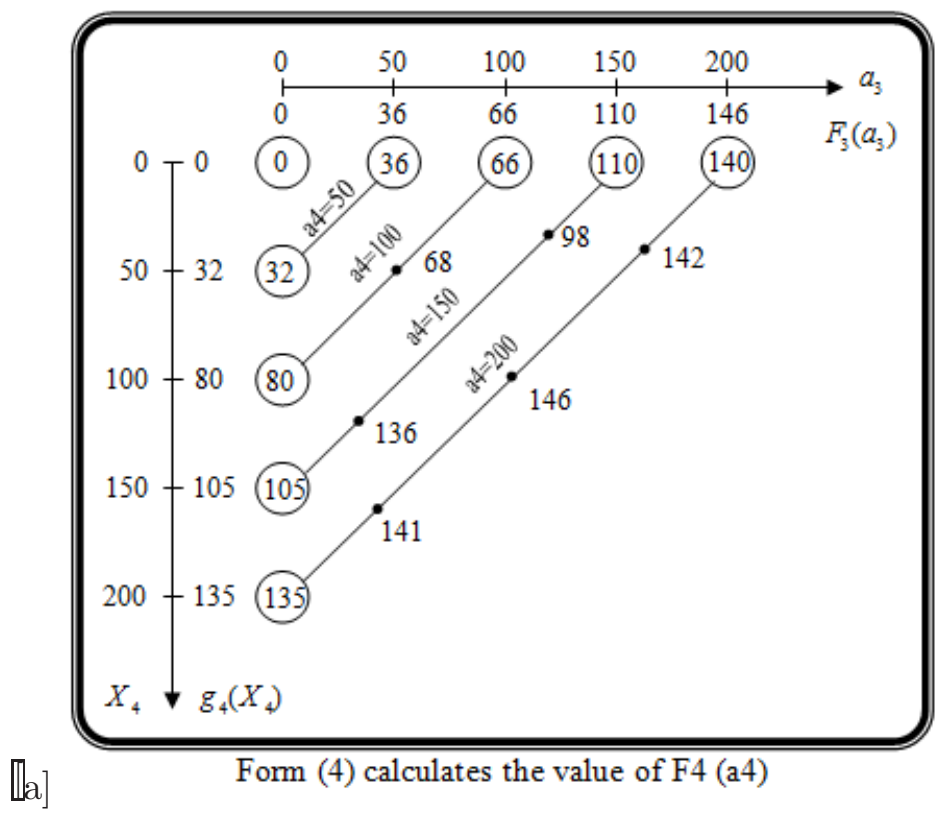

As for the variables $X_{4}, A_{3}$, it is calculated by the following table: 


\begin{tabular}{|c|c|c|c|}
\hline$A_{4}=A_{3}+X_{4}$ & $F_{4}\left(A_{4}\right)$ & $A_{3}$ & $X_{4}$ \\
\hline 0 & 0 & 0 & 0 \\
50 & 36 & 50 & 0 \\
100 & 66 & 100 & 0 \\
150 & 110 & 0 & 150 \\
200 & 140 & 50 & 150 \\
\hline
\end{tabular}

- For the variable $\left(X_{5}\right)$ :

$$
\begin{aligned}
F_{5}\left(A_{5}\right)= & \operatorname{Max}\left\{\left(g_{5}\left(X_{5}\right)+F_{4}\left(A_{4}\right)\right\}\right. \\
0 \leq X_{5}= & A_{5} \\
= & \operatorname{Max}\left\{g_{5}\left(X_{5}\right)+F_{4}\left(A_{5}-X_{5}\right)\right\} \\
\text { Where } & A_{45}=A_{4}-X_{5}
\end{aligned}
$$

The value of $F_{5}$ account $\left(A_{5}\right)$ for all $A_{5}$ on the basis of the values of the following forms:

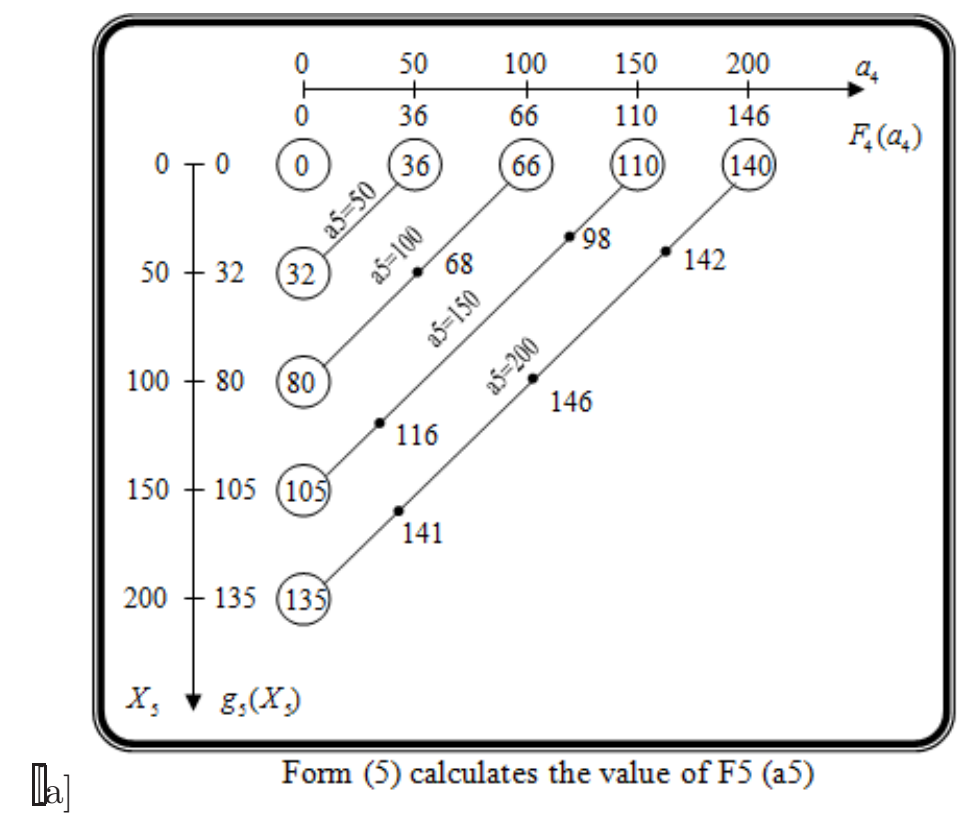

As for the variables $X_{5}, A_{4}$, it is calculated by the following table: 


\begin{tabular}{|c|c|c|c|}
\hline$A_{5}=A_{4}+X_{5}$ & $F_{5}\left(A_{5}\right)$ & $A_{4}$ & $X_{5}$ \\
\hline 0 & 0 & 0 & 0 \\
50 & 36 & 50 & 0 \\
100 & 80 & 0 & 100 \\
150 & 160 & 50 & 100 \\
200 & 146 & 100 & 100 \\
\hline
\end{tabular}

From the above we conclude the following:

- From the table (6) when the $A_{5}=200: A_{4}=100, X_{5}=100$

- From the table (5) when the $A_{4}=100: A_{3}=100, X_{4}=0$

- From the table (4) when the $A_{3}=100: A_{2}=50, X_{3}=50$

- From the table (3) when the $A_{2}=50: A_{1}=0, X_{2}=50$

Based on the foregoing, when the $A_{5}=200$, the basic values of the variables take the following values: The optimum value of the annual increase in production, it is calculated as follows:

A monetary unit $F_{5}\left(A_{5}\right)=146$. In the same way is to identify the core values of the variables when values $\left(A_{5}\right)$ as follows:

$$
A_{5}=150, \quad A_{5}=100, \quad A_{5}=50, \quad A_{5}=0 .
$$

The final results are presented for the problem through the following table:

\begin{tabular}{|c|c|c|c|c||c||c|}
\hline$A_{5}$ & $X_{1}$ & $X_{2}$ & $X_{3}$ & $X_{4}$ & $X_{5}$ & $F_{5}\left(A_{5}\right)$ \\
\hline 0 & 0 & 0 & 0 & 0 & 0 & 0 \\
50 & 0 & 0 & 50 & 0 & 0 & 36 \\
100 & 0 & 0 & 0 & 0 & 100 & 80 \\
150 & 0 & 0 & 50 & 0 & 100 & 116 \\
200 & 0 & 50 & 50 & 0 & 100 & 146 \\
\hline
\end{tabular}

\section{Conclusion:}

Based on the foregoing discussion, the following conclusions are clear: The value of capital expenditures takes (200) A monetary unit, and each line of productive $\mathrm{A} 2$ and $\mathrm{A} 3$ production lines takes the amount of 50 thousand units in cash. 
The production line A5 takes the value (100) A monetary unit, and it is the maximum value of the total annual production increases of 146 thousand units in cash. However, if the capital expenditure takes the value (100) thousand units of cash, allocating these expenses to the line of productive A5 is best. Moreover, this decision leads to become the maximum value of the annual increase of production (80) A monetary unit and for the rest of the indicators and figures related to other possibilities values a5. Thus, the ready-made garment factory management in Najaf and, in particular, the management of production rely on quantity to rationalize the investment decisions. These decisions relate to the five production lines at its disposal to cope with the modification that occurred in the mode of production of civilian products, which are similar to the same coarse and cruel nature of military products.

\section{References}

[1] Alfahdel, Muied Abed Alhusain. Production Planning and Control. Mars Publishing House, Riyadh, Saudi Arabia.(2007).

[2] Alfahdel, Muied Abed Alhusain.Qualitative and Quantitative Methods to Support Regulatory Decisions. Warraq Foundation Publishing, Amman, Jordan.(2008).

[3] Alfahdel, Muied Abed Alhusain. A quantitative Approach to Time Management. Mars Publishing House, Riyadh, Saudi Arabia.(2008).

[4] Alfahdel, Muied Abed Alhusain. Accounting Operations Research. Enrich the House Publishing, Riyadh, Saudi Arabia.(2008).

[5] VAlfaeath, Mahmoodand Qedada, Esa. Operations Research. Dar Yazouri Scientific publication and distribution, Amman, Jordan.(2007).

[6] Abramowitz, Irving, Production Management. New York, The Ronald press Co.(1999).

[7] Brown, Steve, Kate Blackmon, Paul Cousins and Harvey Maylor.OPERATIONS MANAGEMENT Policy, Practice and Performance Improvement. Butterworth-Heinemann Linacre House, Jordan Hill, Oxford OX2 8DP. (2001).

[8] Daft, R. L. and Noe, Raymond A.Organizational Behavior. Harcourt College Publishers, $(2001)$.

[9] Brown, Steve, Lamming, Richard, Bessant, John and Peter Jones. Strategic Operations Management El Sevier Butterworth-Heinemann, Linacre House, Second edition, Jordan Hill.(2005).

[10] Heizer, Jay. Operations Management. 10th ed., Boston Columbus Indianapolis New York, San Francisco.(2011).

[11] Hussey, David. Management Training and Strategy, How to Improve Competitive performance. (Oxford: Pergamum press).(1988)

[12] Krajewski, Lee J., Ritzman, Larry R., Malhotra, Manojk K. Operations Management Processes and supply Chains.9 ed, Courier, Kendallville le,(2010). 
[13] Kumar, S, Anil and N, Suresh, production and operations Management, New Age International (P) Ltd., Publishers,(2008).

[14] Martinich, Joseph. Productions and Operations Management. An Applied Modem Approach, New York, John Wiley and Sons.(1997).

[15] J2.Mertins, Knowledge management: Bost Practices in Europe. Springer-Veriage, Berlin: Heidelberg(2001).

[16] Roy, Ram Naresh.Production Management. Published by New Age International (P) Ltd., Publishers. (2005). bibitemm90 P.Borowiak, Warsaw. Operations Management. Poland. (2011).

[17] Salawsk. Operations Management. International bible societyPWN, W-WA.(2010).

[18] Stevenson. William J. Operations Management. The Eleventh Editio, McGrawHill.(2011).

[19] Sumanth, David. Productivity Engineering Management. New York: McGrawHill.(1999).

[20] Telsang Martand.Production Management. Chand and company ltd, ram nagar, New Delhi.(2008).

[21] A Guide to Integrated Management of Productivity Activities (IMPACT. Spring Singapore, enabling enterprise, Fusion polis Walk, 01-02 South Tower, Solaris),(2011).

[22] Barman, Himadri.Centre for Management Studies.Dibrugarh University, www google.iq/search.(1997).

[23] Diana Mross, Sandra Rothenberg. Ph.D. Formulation and Implementation of Environmental Strategies. RIT Rochester, NY.(2006).

[24] Farooq, Syed Umar. Time. Management. The Art of Enhancing Productivity and Efficiency Journal of Managerial Sciences, Volume II, Number 2.(2000).

[25] Hassanali, Kevin. N.A. Productivity Model Utilizing a Work Study Approach for Performance Measurement.The Journal of the Association of Professional Engineers of Trinidad and Tobago Vol.40, No.1.(2011). 